\title{
Multiple short courses of corticosteroids in children
}

Tristan Harding, Anton Harding

\section{Background}

Corticosteroids are adrenal steroid hormones responsible for immune homeostasis, blood pressure regulation, energy and appetite regulation, and suppression of inflammation. Oral corticosteroids ('steroids') are commonly used in children for a number of medical conditions, including asthma, croup, inflammatory bowel disease and nephrotic syndrome. There has been some concern about potential side effects of oral, topical or inhaled steroids, including reduction in growth, weight gain, behavioural changes and immunosuppression resulting in infection.

\section{Objective}

While many recent studies have assessed individual risks, this article aims to provide an overview of steroid use in common paediatric presentations, highlighting current management and risks associated with recurrent doses of steroids in the paediatric population.

\section{Discussion}

Short courses of oral steroids (less than two weeks) in children are very unlikely to cause long-term side effects in children. Children requiring courses more than two weeks' duration warrant specialist referral and a weaning plan to reduce adrenal suppression and insufficiency.
CORTICOSTEROIDS ('steroids') are adrenal steroid hormones responsible for modulation of a number of physiological functions, including suppression of inflammation, immune homeostasis, mobilisation of energy, appetite regulation and blood pressure homeostasis. ${ }^{1-2}$ Despite their efficacy, there are multiple potential side effects of steroids, particularly with continuous long-term use ( $>6$ weeks), high dose ( $>2 \mathrm{mg} / \mathrm{kg}$ prednisolone equivalent) or repeated use (at least monthly). Health practitioners need to be mindful of this, particularly when prescribing multiple repeats of oral steroids for use in the community. This article examines the risks and benefits of steroid use in children. While not covered in this article, it is important to note that inflammatory bowel disease, idiopathic juvenile arthritis and nephrotic syndrome, among other conditions, will likely require longer-term systemic steroids; accordingly, health practitioners should be aware of potential side effects and discuss with specialists as required.

Parental attitudes towards steroid use can direct treatment and determine adherence. A Malaysian study of parents whose children were on prophylactic inhaled steroids revealed $91 \%$ of parents held concerns over steroid side effects, while $86 \%$ were worried about their child becoming dependent on inhalers. ${ }^{3}$ Of those parents who were concerned about steroid therapy, their children were also more likely to miss doses and require nebulised therapy when compared with children whose parents were less concerned. This article addresses some of these concerns.
Steroids have been known for decades to affect growth, ${ }^{4-6}$ through a variety of mechanisms, including disruption to collagen and bone formation, as well as altered secretion and action of growth hormone. ${ }^{5}$ Both endogenous and exogenous steroids have showed growthretarding effects. Prader et $\mathrm{al}^{7}$ describe a young girl with Cushing syndrome due to an adrenal adenoma, whose significant growth restriction corrected with removal of the tumour. In a study of 224 children with cystic fibrosis receiving either alternate-day prednisolone or placebo for up to four years, final height was reduced by $4 \mathrm{~cm}$ in boys treated with either high dose $(2 \mathrm{mg} / \mathrm{kg}$ to maximum $60 \mathrm{mg}$ ) or low dose $(1 \mathrm{mg} / \mathrm{kg})$ prednisolone when compared with control after the age of 18 years, with no similar persistent growth impairment seen in girls. ${ }^{8}$ While acknowledging nutritional deficiencies in cystic fibrosis, studies such as these highlight the potential side effects of excessive steroids, and have led to concerns regarding recurrent exogenous steroid use in children. Importantly, there is no evidence to suggest any adverse impacts on growth from multiple short courses of steroids in children.

Box 1. Benefits of oral corticosteroids in paediatric asthma management

- Reduction in length of hospital stay ${ }^{14}$

- Reduction in risk of relapse ${ }^{11,45}$

- Reduction in need for admission of school-aged children in the emergency setting ${ }^{15}$

- Improved quality of life 22 
Multiple types of oral steroids are commonly used in children. Dexamethasone (36-54 hours) has a longer biological half-life than prednisolone (18-36 hours); hydrocortisone (6-12 hours) has the shortest half-life. As shown in Table $1,100 \mathrm{mg}$ hydrocortisone is equivalent to $25 \mathrm{mg}$ prednisolone and $4 \mathrm{mg}$ dexamethasone. ${ }^{9}$ Extent of linear growth inhibition is related to the steroid used, with longer-acting steroids more likely to affect growth; ${ }^{10}$ dose and duration of exposure determine the extent, which is most pronounced when administered daily rather than alternate daily. ${ }^{5}$

\section{Asthma}

Asthma is one of the most common reasons for children presenting to general practice in Australia. ${ }^{11}$ One in nine Australians (11.2\%) have asthma, with asthma more common among boys (12.1\%) than girls (7.9\%) aged up to 14 years. ${ }^{12}$

Many of the patients presenting to general practice will have mild to moderate asthma, with normal mental state, some increased work of breathing (intercostal or subcostal recession, tracheal tug), and still able to talk with minimal limitations. In most cases, these can be managed with $\beta 2$-agonists (such as salbutamol) and oral steroids (prednisolone).

\section{Systemic steroids}

While salbutamol is widely accepted as primary management, treatment with systemic steroids has been shown to reduce the risk of relapse in children. ${ }^{13,14}$ Prednisolone is the most commonly prescribed steroid for asthma. ${ }^{15} \mathrm{~A}$ Lancet randomised trial of children aged 2-5 years presenting to an emergency department demonstrated a clear benefit of prednisolone $(1 \mathrm{mg} / \mathrm{kg} /$ day for three days) over placebo at reducing length of hospital stay. ${ }^{16}$ Previous studies have demonstrated oral steroids administered within one hour of presentation reduced the need for admission for children with asthma. ${ }^{17}$ Other benefits are outlined in Box 1.

There is some debate about the dosing of systemic steroids for children presenting with signs and symptoms of asthma, reflected by the inconsistencies of protocols in many articles. The National Asthma Council Australia ${ }^{18}$ recommends oral prednisolone $1 \mathrm{mg} / \mathrm{kg}$ for three days for children aged 6- 11 years (to a maximum of $50 \mathrm{mg}$ ). For children aged 1-5 years, steroid use should be avoided unless severe acute wheezing requiring admission to hospital is present.

Conversely, the clinical practice guideline for acute asthma published by the Royal Children's Hospital, Melbourne, recommends a single dose of $2 \mathrm{mg} / \mathrm{kg}$ (maximum $60 \mathrm{mg}$ ) oral prednisolone, only continuing with $1 \mathrm{mg} / \mathrm{kg}$ daily for one to two days if there is an ongoing need for regular salbutamol, ${ }^{19}$ based on the Thoracic Society of Australia and New Zealand position statement $2010 .{ }^{20}$ These authors recommend this regimen for optimal management. In the community setting, long-term oral steroids (ie for more than 10 days) warrants referral to a paediatrician or paediatric respiratory physician. ${ }^{21}$

An Australian study compared threeand five-day courses of oral prednisolone ( $1 \mathrm{mg} / \mathrm{kg}$ to maximum $50 \mathrm{mg}$ ) for 201 children not requiring an admission to hospital. ${ }^{22}$ The researchers found no difference in the proportion of patients symptom free at day seven, their primary outcome. Neither group had any statistically significant difference in quality of life.
Ordinarily, single courses of oral steroids should not be a trigger for a prescription for inhaled steroids. However, two courses of oral steroids in two successive months warrants escalation of therapy, as does interval symptoms and a frequent (at least weekly) reliance on salbutamol. More than four courses over a period of 12 months requires evaluation of an underlying diagnosis and optimisation of management. These authors would recommend the lowest tolerated dose of inhaled steroids that improves symptoms, for a short (2-3-month) trial. Patients should be encouraged to rinse their mouth after each dose. If the lowest dose is insufficient after a two-week trial, the dose or frequency of administration should be increased. Should this also fail to achieve acceptable results, a long-acting beta-agonist can be added.

Parents sometimes initiate oral steroids as part of asthma management at home. This approach has been shown to reduce the number of missed school days and asthma symptoms. ${ }^{23}$ The Pharmaceutical Benefits Scheme (PBS) allows up to five repeats of oral prednisolone on a PBS script ${ }^{24}$ health practitioners need to be mindful that parent initiation of steroids may not be noted on a child's health records because of acuity of presentations presenting to a different general practice or directly to the emergency department. Parents should be encouraged to diarise the frequency and duration (number of days) of steroid use. Further, parent-initiated steroids are not recommended for preschool children, as they are not effective at symptom management in this age group. ${ }^{25}$

\section{Inhaled corticosteroids}

Children with frequent episodic asthma or regular interval symptoms are commonly

Table 1. Relative potencies (approximate dose equivalent to $25 \mathrm{mg}$ prednisolone) and half-lives of commonly used oral steroids

\begin{tabular}{llll}
\hline Oral steroid & Approximate dose equivalent & Duration of action & Biological half-life \\
\hline Hydrocortisone & $100 \mathrm{mg}$ & Short acting & $6-12$ hours \\
\hline Prednisolone & $25 \mathrm{mg}$ & Intermediate & $18-36$ hours \\
\hline Dexamethasone & $4 \mathrm{mg}$ & Long acting & $36-54$ hours \\
\hline
\end{tabular}


prescribed inhaled steroids to minimise the frequency and severity of asthma attacks. While the focus of this review is to assess the effects of repeated short courses of oral steroids, it is important to acknowledge that high-dose inhaled steroids (Table 2) can also have significant long-term side effects. While montelukast has been considered as a precursor to commencing inhaled steroids, ${ }^{21}$ recent commentary has questioned this, given limited evidence. ${ }^{26}$ This should generally be used as an alternative to steroids in the management of inhaled allergens, noting that sleep disturbance is the most common side effect.

A Cochrane review dismissed the notion that acutely increasing the dose of inhaled steroids can manage asthma flare-ups in children aged $<12$ years. ${ }^{27}$ Furthermore, doubling or quadrupling the dose of inhaled steroids did not prevent severe flare-ups in any age group. ${ }^{27} \mathrm{~A}$ small study of 129 children aged up to six years using high-dose inhaled fluticasone showed that, while there was less rescue oral steroid in the treatment group when compared with placebo, there were significant implications for growth, with reduced gain in height when compared with placebo. ${ }^{28}$ Inhaled steroids cause a statistically significant increase in body mass index trajectory in children with moderate to severe asthma receiving high-dose steroids when compared with low-dose steroids. ${ }^{29}$ Despite this, it is important that health professionals remind patients to continue to take their inhaled steroid preventer with a spacer during oral steroid therapy. ${ }^{21}$
Improved compliance should reduce exacerbations and therefore minimise rescue steroid use. Additionally, it is important for the general practitioner to regularly review the dose of corticosteroids and use the lowest dose providing benefit. Given the seasonal nature of viral-induced wheeze in children, consider weaning preventive inhaled steroids over summer months. Given the increased burden of obesity, providing appropriate diet and lifestyle advice is imperative.

\section{Side effects}

Side effects of systemic steroids are well documented (Table 3). Vomiting (5.4\%), behaviour disturbance (4.7\%) and sleep disturbance $(4.3 \%)$ are the most common adverse drug reactions ${ }^{30}$ from short courses of steroids. Other short-term side effects include nausea, abdominal pain, facial swelling/erythema and other gastrointestinal disturbances. ${ }^{18,30}$ Increased appetite, weight gain and indigestion are also common. Sleep disturbance can be minimised by avoiding administration later in the day.

Immunosuppression leading to infection is one of the most serious adverse drug reactions associated with prolonged oral steroid use. A review of the literature suggested that up to $1 \%$ of patients experience infection, with one documented death and other children admitted to intensive care units with severe complications of varicella zoster. ${ }^{30}$ Two weeks of treatment with a moderate ( $2 \mathrm{mg} / \mathrm{kg} /$ day) dose of oral prednisolone may result in immune suppression; however, this is not seen in shorter courses of five days or less. ${ }^{1}$ Dose tapering is not required unless treatment duration exceeds two weeks. ${ }^{18}$ Reassuringly, a meta-analysis showed no statistically significant differences between systemic or inhaled steroid when compared with placebo for severe infections, systemic infections, or upper and lower respiratory tract infections. ${ }^{6}$

A potential complication of recurrent short courses of steroids is suppression of the hypothalamic-pituitary-adrenal (HPA) axis. One month of 1-2 mg/kg/day prednisolone may be sufficient to cause adrenal suppression lasting for up to one year. ${ }^{1}$ This was not shown after a five-day course of $1-2 \mathrm{mg} / \mathrm{kg} /$ day prednisolone. ${ }^{1}$ One in five children who have at least four courses of systemic steroids per year (for any indication) are susceptible to suppression of the HPA axis, as shown by a suboptimal response to an insulin and adrenocorticotropic hormone challenge, ${ }^{31}$ but is not clinically relevant despite biochemical evidence. As many as $81 \%$ of children receiving short-course oral steroids have shown biochemical suppression of the HPA axis. ${ }^{30}$ A 2019 review from South Africa suggested that any child receiving steroids is at risk of HPA axis suppression and warrants investigation. ${ }^{32}$ This is not in keeping with Australian guidelines and, given limited evidence, should be interpreted with caution.

A meta-analysis suggested that, despite limitations in pooling data, any growth impacts from steroid use are

Table 2: Suggested low, medium and high paediatric doses of inhaled corticosteroids for treatment of asthma (adapted from NICE guideline 2018) ${ }^{48}$

\begin{tabular}{|c|c|c|c|}
\hline & Paediatric low dose & Paediatric moderate dose & Paediatric high dose \\
\hline $\begin{array}{l}\text { Beclomethasone dipropionate } \\
\text { extra-fine particle inhalers }\end{array}$ & $\begin{array}{l}100 \mu \mathrm{g} \text { per day in two divided } \\
\text { doses }\end{array}$ & $\begin{array}{l}150-200 \mu g \text { per day in two } \\
\text { divided doses }\end{array}$ & $\begin{array}{l}300-400 \mu g \text { per day in two } \\
\text { divided doses }\end{array}$ \\
\hline Budesonide dry powder inhalers & $\begin{array}{l}\text { 100-200 } \mu g \text { per day in a single } \\
\text { dose or two divided doses }\end{array}$ & $\begin{array}{l}300-400 \mu g \text { per day in a single } \\
\text { dose or two divided doses }\end{array}$ & $\begin{array}{l}500-800 \mu g \text { per day in two } \\
\text { divided doses }\end{array}$ \\
\hline Ciclesonide metered dose inhaler & $80 \mu \mathrm{g}$ per day in a single dose & $\begin{array}{l}160 \mu \mathrm{g} \text { per day in a single dose } \\
\text { or two divided doses }\end{array}$ & $\begin{array}{l}240-320 \mu g \text { per day in two } \\
\text { divided doses }\end{array}$ \\
\hline $\begin{array}{l}\text { Fluticasone propionate metered } \\
\text { dose and dry powder inhalers }\end{array}$ & $\begin{array}{l}100 \mu \mathrm{g} \text { per day in two divided } \\
\text { doses }\end{array}$ & $\begin{array}{l}150-200 \mu g \text { per day in two } \\
\text { divided doses }\end{array}$ & $\begin{array}{l}250-500 \mu \mathrm{g} \text { per day in two } \\
\text { divided doses }\end{array}$ \\
\hline
\end{tabular}




\section{Table 3. Potential side effects of short courses of oral steroids, and the longer-term potential effects of recurrent use $e^{1,30,49}$}

\begin{tabular}{l}
$\begin{array}{l}\text { Potential side effects of short } \\
\text { of oral steroids }\end{array}$ \\
\hline - Sleep disturbance \\
- Behavioural disturbance \\
- Vomiting \\
- Gastritis \\
- Gastrointestinal disturbance \\
- Facial flushing \\
- Nocturia \\
- Dry skin
\end{tabular}

Effects of long-term dosing

with steroids

- Weight gain

- Cushingoid facies

- Osteoporosis

- Cataracts

- Hypertrichosis

- Cutaneous atrophy
- Mood changes (irritability, hyperactivity)

- Reduction in final height or growth velocity

- Hypertension

- Hypothalamic-pituitary-adrenal axis suppression

small (sub-centimetre) ${ }^{6}$ A retrospective study of long-term (five-year) low- and medium-dose inhaled steroid use did not show growth deceleration in prepubertal children. ${ }^{33}$ A dose-dependent reduction in bone mineral accretion as well as increased risk of osteopenia was shown in boys but not in girls following repeated exposure to short courses of oral steroids over several years. ${ }^{34}$ Systemic steroids have also been associated with increased odds of paediatric fractures. ${ }^{35}$ The minimal loss of final height needs to be weighed against the potential benefits from steroids, which include reduction in hospital admissions, reduction in severity of asthma flares and better quality of life.

\section{Other side effects}

Behavioural disturbances are a well-recognised side effect of steroid use. A review suggested that higher doses of steroids may exacerbate these behaviours; however, disease severity and environmental stressors make this multifactorial. ${ }^{36}$ Two meta-analyses in adult patients with severe asthma showed links with sepsis, thromboembolism and fracture following both short ${ }^{37}$ and prolonged ${ }^{38}$ courses of oral steroids, but further research is required to correlate these findings in children.

Despite these side effects, oral steroids remain the only accepted, effective treatment for acute asthma and play an important part in managing severe asthma. ${ }^{39}$

There has been recent debate about the efficacy of dexamethasone in asthma management. A randomised trial comparing two doses of dexamethasone to five days oral prednisolone for children presenting to the emergency department showed that dexamethasone was not an inferior option. ${ }^{40}$ National Asthma Council Australia suggests a single dose of $0.6 \mathrm{mg} / \mathrm{kg}$ dexamethasone as an alternative to prednisolone (maximum dose $16 \mathrm{mg}$ ); this can be repeated the following day if required, but should not exceed two days of treatment. ${ }^{18}$

Studies have suggested that oral dexamethasone may be better tolerated than oral prednisolone in acute asthma management. Qureshi et al compared oral prednisolone $(2 \mathrm{mg} / \mathrm{kg}$ initially then a further four days $1 \mathrm{mg} / \mathrm{kg}$ ) with oral dexamethasone (two doses of $0.6 \mathrm{mg} / \mathrm{kg}$ to maximum $16 \mathrm{mg}$ ) in a population of 533 children aged $2-18$ years. ${ }^{41}$ Dexamethasone was associated with less vomiting than prednisolone, likely a result of reduced frequency of dosing resulting in a statistically significant increase in compliance. While compliance is often a result of personal and patient-related factors, these are modifiable with positive reinforcement from the

\section{Alternative steroid therapies}

medical visit with good communication and sufficient information. ${ }^{42}$ More children missed at least two days of school when treated with prednisolone, compared with dexamethasone. ${ }^{41}$

\section{Croup}

Croup, or laryngotracheobronchitis, is inflammation of the upper airway, larynx and trachea, ${ }^{43}$ mostly a result of viral infections. Most presentations tend to occur in children aged six months to six years, with symptoms commonly worse at night. ${ }^{43}$ Systemic steroids are frequently prescribed to manage croup. In this setting, steroids have been shown to be effective in preventing escalation of therapy, including the need for nebulised adrenaline or intubation and ultimately reducing duration of hospital stays. ${ }^{44}$ A Western Australian randomised controlled trial ${ }^{45}$ showed non-inferiority for both low-dose dexamethasone $(0.15 \mathrm{mg} / \mathrm{kg})$ and prednisolone $(1 \mathrm{mg} / \mathrm{kg})$ when compared with the 'gold standard' $0.6 \mathrm{mg} / \mathrm{kg}$ dexamethasone. This trial showed similar outcomes in all treatment groups for duration of stay, recurrent presentations, use of nebulised adrenaline and adverse events. ${ }^{45}$

\section{Eczema}

Oral steroids are not used to manage eczema. While topical steroids may have side effects and their use is often recommended judiciously, a consensus statement recommends ample use of steroid to cover the affected areas of skin, once or twice per day, until resolution. Adrenal suppression is unlikely to occur if used in short, sharp courses, which is recommended treatment by dermatologists. Irreversible skin thinning, osteopenia, hypertrichosis, hypopigmentation and tachyphylaxis do not occur in children when adhering to appropriate doses of topical steroids. ${ }^{46}$

\section{Conclusion}

The use of steroids is widely accepted for treatment of multiple paediatric presentations to general practice. When 
used as per current protocols, clinically relevant long-term side effects should not occur. While behavioural changes and sleep disturbances, including unpleasant dreams, may be seen in the short term, ${ }^{30}$ these are reduced by once-daily morning dosing. ${ }^{47}$ Steroids are safe, accepted and effective, even when used as multiple short courses.

\section{Key points}

- Short courses of oral steroids are commonly used in children with asthma and croup, but longer durations may be used for other conditions.

- If used as per current protocols, short courses of oral steroids are very unlikely to cause long-term side effects.

- Dose tapering is not required for courses under two weeks' duration.

- If managed on prolonged courses of oral steroids (at least two weeks), consider specialist referral.

- Oral steroid use in preschool children with respiratory complaints should be avoided in the community setting unless the patient is being referred to an emergency department.

- Oral steroids remain an accepted, effective treatment for acute asthma and croup.

\section{Authors}

Tristan Harding BSc, MSc, MD, Paediatric Registrar, The Royal Children's Hospital, Vic Anton Harding BSc (Hons), MBBS, FRACP, Consultant Paediatrician and Endocrinologist, The Royal Children's Hospital, Vic

Competing interests: None.

Funding: None.

Provenance and peer review: Commissioned, externally peer reviewed.

\section{Correspondence to:}

tristanharding@me.com

\section{References}

1. Reider MJ. The child with multiple short courses of steroid therapy. Paediatr Child Health 2003;8(4):226. doi: 10.1093/pch/8.4.226.

2. Ferrara G, Petrillo MG, Giani T, et al. Clinical use and molecular action of corticosteroids in the pediatric age. Int J Mol Sci 2019;20(2):444. doi: 10.3390/ijms20020444

3. Chan PW, DeBruyne JA. Parental concern towards the use of inhaled therapy in children with chronic asthma. Pediatr Int 2001;42(5):547-51. doi: 10.1046/j.1442-200x.2000.01278.x.

4. Preece MA. The effect of administered corticosteroids on the growth of children. Postgrad Med J 1976;52(612):625-30. doi: 10.1136/ pgmj.52.612.625.
5. Allen DB. Growth suppression by glucocorticoid therapy. Endocrinol Metab Clin North Am 1996:25(3):699-717. doi: 10.1016/s08898529(05)70348-0.

6. Fernandes RM, Wingert A, Vandermeer B, et al. Safety of corticosteroids in young children with acute respiratory conditions: A systematic review and meta-analysis. BMJ Open 2019;9(8):e028511. doi: 10.1136/bmjopen-2018-028511.

7. Prader A, Tanner JM, von Harnack GA. Catch up growth following illness or starvation. An example of developmental canalization in man. J Pediatr 1963;62:646-59. doi: 10.1016/s00223476(63)80035-9.

8. Lai HC, FitzSimmons SC, Allen DB, et al. Risk of persistent growth impairment after alternate-day prednisolone treatment in children with cystic fibrosis. N Engl J Med 2000;342(12):851-59. doi: 10.1056/NEJM200003233421204.

9. Meikle AW, Tyler FH. Potency and duration of action of glucocorticoids. Effects of hydrocortisone, prednisolone and dexamethasone on human pituitary-adrenal function. Am J Med 1977;63(2):200-07. doi: 10.1016/00029343(77)90233-9.

10. Richmond EJ, Rogol AD. Causes of short stature. Waltham, MA: UpToDate Inc, 2020. Available at www.uptodate.com/contents/causes-of-shortstature [Accessed 23 July 2020].

11. Henderson J, Charles J, Pan Y, Bayram C, Miller G, Britt H. Management of childhood asthma in general practice. Aust Fam Physician 2015;44(6):349-51.

12. Australian Bureau of Statistics. National health survey: First results 2017-18. Belconnen, ACT: ABS, 2018.

13. Castro-Rodriguez JA, Rodrigo GJ, Rodríguez-Martínez CE. Principal findings of systematic reviews of acute asthma treatment in childhood. J Asthma 2015;52(10):1038-45. doi: 10.3109/02770903.2015.1033725.

14. Kirkland SW, Vandermeer B, Campbell $S$, et al. Evaluating the effectiveness of systemic corticosteroids to mitigate relapse in children assessed and treated for acute asthma: A network metaanalysis. J Asthma 2019;56(5):522-33 doi: 10.1080/02770903.2018.1467444.

15. Hendeles L. Selecting a systemic corticosteroid for acute asthma in young children. J Pediatr 2003:142(2 Suppl):S40-44. doi: 10.1067/ mpd.2003.25

16. Foster SJ, Cooper MN, Oosterhof S, Borland $\mathrm{ML}$. Oral prednisolone in preschool children with virus-associated wheeze: A prospective, randomised, double-blind, placebo-controlled study. Lancet Respir Med 2018;6(2):97-106. doi: 10.1016/S2213-2600(18)30008-0.

17. Rowe BH, Spooner C, Ducharme FM, Bretzlaff JA, Bota GW. Early emergency department treatment of acute asthma with systemic corticosteroids. Cochrane Database Syst Rev 2001;(1):CD002178. doi: 10.1002/14651858. CD002178.

18. Australian Asthma Handbook. Starting systemic corticosteroid treatment. South Melbourne, Vic: National Asthma Council Australia, 2019. Available at www.asthmahandbook.org.au/acuteasthma/clinical/corticosteroids [Accessed 23 July 2020].

19. The Royal Children's Hospital Melbourne. Clinical practice guideline: Asthma acute. Parkville, Vic: The Royal Children's Hospital Melbourne, 2018. Available at www.rch.org.au/clinicalguide/ guideline_index/Asthma_acute [Accessed 23 July 2020].
20. Van Asperen PP, Mellis CM, Sly PD. The role of corticosteroids in the management of childhood asthma. Med J Aust 2002;176(4):168-73.

21. Australian Asthma Handbook. Managing flare-ups in children aged 6 years and over. South Melbourne, Vic: National Asthma Council Australia, 2019. Available at www. asthmahandbook.org.au/management/ children/6-years-and-over/flare-ups [Accessed 23 July 2020].

22. Chang $A B$, Clark $R$, Sloots TP, et al. A 5-versus 3-day course of oral corticosteroids for children with asthma exacerbations who are not hospitalised: A randomised controlled trial. Med J Aust 2008;189(6):306-10. doi: 10.5694/j.13265377.2008.tb02046.x.

23. Vuillermin P, Robertson CF, Carlin JB, Brennan SL, Biscan MI, South M. Parent initiated prednisolone for acute asthma in children of school age: Randomised controlled crossover trial. BMJ 2010;340:c843. doi: 10.1136/bmj.c843.

24. Pharmaceutical Benefits Scheme. Pharmaceutical Benefits Scheme (PBS). Canberra, ACT: Department of Health, 2020. Available at www.pbs.gov.au/pbs/ home;jsessionid=1g4m8s 177 oh9iydkfyhtbr5rf [Accessed 23 July 2020].

25. Abrams EM, Becker AB, Szefler SJ. Use of oral corticosteroids in the wheezy toddler. J Pediatr 2018;201:16-20. doi: 10.1016/j.jpeds.2018.06.011.

26. Harding TW, Harding AG. Role of montelukast in management of episodic viral wheeze. J Paediatr Child Health 2017;53(12):1240-41. doi: 10.1111/ jpc.13797.

27. Kew KM, Quinn M, Quon BS, Ducharme FM Increased versus stable doses of inhaled corticosteroids for exacerbations of chronic asthma in adults and children. Cochrane Database Syst Rev 2016;(6):CD007524. doi: 10.1002/14651858.CD007524.pub4.

28. Ducharme FM, Lemire C, Noya FJ, et al. Pre-emptive use of high-dose fluticasone for virus-induced wheezing in young children. N Engl J Med 2009;360(4):339-53. doi: 10.1056/ NEJMoa0808907.

29. Han J, Nguyen J, Kim Y, et al. Effect of inhaled corticosteroid use on weight (BMI) in pediatric patients with moderate-severe asthma. J Asthma 2019;56(3):263-69. doi: 10.1080/02770903.2018.1455853.

30. Aljebab F, Choonara I, Conroy S. Systematic review of the toxicity of short-course oral corticosteroids in children. Arch Dis Child 2016:101(4):365-70. doi: 10.1136/archdischild-2015-309522.

31. Dolan LM, Kesarwala HH, Holroyde JC, Fischer TJ. Short-term, high-dose, systemic steroids in children with asthma: The effect on the hypothalamic-pituitary-adrenal axis. J Allergy Clin Immunol 1987;80(1):81-87. doi: 10.1016/s00916749(87)80195-1.

32. Zöllner EW. Asthma treatment in children: A guide to screening for and management of hypothalamic-pituitary-adrenal axis suppression. S Afr Med J 2019;109(5):306-09. doi: 10.7196/ SAMJ.2019.v109i5.13932

33. Hatziagorou E, Kouroukli E, Avramidou V, et al. A 'real life' study on height in prepubertal asthmatic children receiving inhaled steroids. J Asthma 2018;55(4):437-42. doi: 10.1080/02770903.2017.1336243.

34. Kelly HW, Van Natta ML, Covar RA, Tonascia J, Green RP, Strunk RC. The effect of long-term corticosteroid use on bone mineral density in children: A prospective longitudinal assessment in the childhood asthma management program (CAMP) study. Pediatrics 2008;122(1):e53-e61. doi: 10.1542/peds.2007-3381. 
35. Gray N, Howard A, Zhu J, Feldman LY, To T. Association between inhaled corticosteroid use and bone fracture in children with asthma. JAMA Pediatr 2018;172(1):57-64. doi: 10.1001/ jamapediatrics.2017.3579.

36. Stuart F, Segal T, Keady S. Adverse psychological effects of corticosteroids in children and adolescents. Arch Dis Child 2005;90(5):500-06. doi: 10.1136/adc.2003.041541.

37. Waljee AK, Rogers MAM, Lin P, et al. Short term use of oral corticosteroids and related harms among adults in the United States: Population based cohort study. BMJ 2017;357:j1415. doi: 10.1136/bmj.j1415.

38. Lefebvre $\mathrm{P}$, Duh MS, Lafeuille $\mathrm{MH}$, et al. Acute and chronic systemic corticosteroid-related complications in patients with severe asthma. J Allergy Clin Immunol 2015;136(6):1488-95. doi: 10.1016/j.jaci.2015.07.046.

39. Ramsahal JM, Wark PA. Appropriate use of ora corticosteroids for severe asthma. Med J Aust 2018;209(S2):S18-S21. doi: 10.5694/mja18.00134.

40. Paniagua N, Lopez R, Muñoz N, et al. Randomized trial of dexamethasone versus prednisolone for children with acute asthma exacerbations. J Pediatr 2017;191:190-96e.1. doi: 10.1016/j. jpeds.2017.08.030.

41. Qureshi F, Zaritsky A, Poirier MP. Comparative efficacy of oral dexamethasone versus oral prednisolone in acute pediatric asthma. J Pediatr 2001;139(2):20-26. doi: 10.1067/mpd.2001.115021.

42. Tilly-Gratton A, Nadon MA, Houle $A$ Peláez S, Ducharme FM. What convinces parents of children with asthma to adhere to maintenance inhaled corticosteroids? Can J Resp Crit Care Sleep 2018:2(3):147-54. doi: 10.1080/24745332.2018.1450101.

43. The Royal Children's Hospital Melbourne. Clinical practice guideline: Croup (laryngotracheobronchitis). Parkville, Vic: The Royal Children's Hospital Melbourne, 2019. Available at www.rch.org.au/clinicalguide/ guideline_index/Croup_Laryngotracheobronchitis [Accessed 23 July 2020].

44. Oritz-Alvarez O. Acute management of croup in the emergency department. Paediatr Child Health 2017;22(3):166-69. doi: 10.1093/pch/pxx019.

45. Parker CM, Cooper MN. Prednisolone versus dexamethasone for croup: A randomized controlled trial. Pediatrics 2019:144(3):e20183772. doi: 10.1542/peds.2018-3772.

46. Mooney E, Rademaker M, Dailey R, et al. Adverse effects of topical corticosteroids in paediatric eczema: Australasian consensus statement. Med Today 2015;16(12):40-50.

47. Liu D, Ahmet A, Ward L, et al. A practical guide to the monitoring and management of the complications of systemic corticosteroid therapy. All Asth Clin Immun 2013;9(30):30. doi: 10.1186/1710-1492-9-30.

48. National Institute for Health and Care Excellence. Inhaled corticosteroid doses for NICE's asthma guideline. London, UK: NICE, 2018.

49. The Royal Children's Hospital Melbourne. Kids health information: Corticosteroid medicine. Parkville, Vic: The Royal Children's Hospital Melbourne, 2018. Available at www.rch.org.au/ kidsinfo/fact_sheets/Corticosteroid_medicine [Accessed 23 July 2020]. 